\title{
The Course Thicknesses of the Great Pyramid
}

\author{
Douglas McKenzie ${ }^{1}$
}

Published online: 8 April 2016

(C) Kim Williams Books, Turin 2016

\begin{abstract}
Eight sets of course thicknesses for the Great Pyramid are combined into one for an improved estimate of each course's thickness and a smaller standard error than was possible before. It is found that the cubit, palm and finger were used in setting the thicknesses of the courses. Three simple patterns-slopes, ramps and flats-were used when setting the thicknesses along with some exceptions. We do not understand why this was done only that it was. This suggests a higher level of intention during the design process than was previously thought.
\end{abstract}

\section{The Course Thicknesses of the Great Pyramid}

The courses (or layers) of the Great Pyramid (GP) vary widely in height (or thickness) from $20^{\prime \prime}$ to almost $60^{\prime \prime}$. Because there is variation in the heights of the stones for a single course, there has not been an accurate estimate of these heights until now. This new assessment is based on combining 8 sets of measurements that have been made over the past 250 years.

Egyptologists generally consider that the different course thicknesses are adequately explained by the various thicknesses of stone available from the quarries. We will show, however, that when accurate estimates are made of the course thicknesses, simple patterns emerge that cannot be explained just by the availability of stone.

For this study, there are 205 courses which brings us about $20^{\prime}$ short of the original top of the GP, missing about 9 courses and the pyramidion. The appearance of thick courses with thinner courses above them (see Fig. 1 below) is easily seen when looking at the GP and has been noted by many observers.

Douglas McKenzie

mckenziedouglas@gmail.com

17 Vista Way, Denville, NJ 07834, USA 


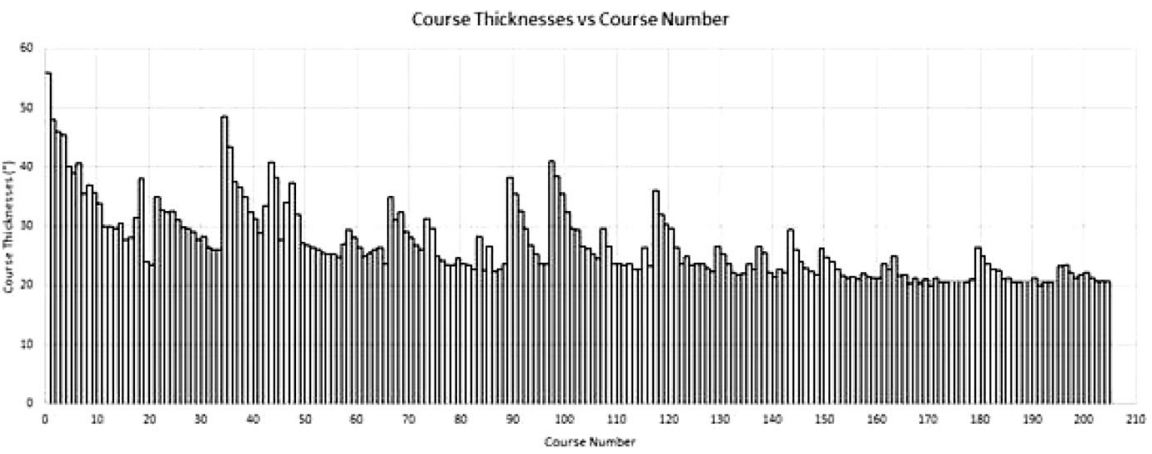

Fig. 1 The course thicknesses plotted vs course number

In this article, we show that it is likely that the designers planned the thicknesses. Specifically, we will show two things:

First, the courses were intended to be integer multiples of the royal cubit, the palm and the finger. The royal cubit is $20.62^{\prime \prime}$. There are 7 palms in a cubit, so each palm is $2.95^{\prime \prime}$. There are 4 fingers in a palm, so each finger is $0.74^{\prime \prime}$. This result is not at all surprising because we know that the GP was designed with the royal cubit. "From [Arnold Dieter's] studies it appears that the ancient Egyptians generally laid out their plans on the basis of simple numbers of cubits, palms and fingers." (Rossi 2007: 60).

What has not been shown, up to this time, is that the course thicknesses follow this same practice. One reason that this has not been demonstrated before is that, up until now, we did not have an accurate assessment of the course thicknesses. This is because of the variations of the stones themselves within one course and the fact that each investigator typically would measure only one stone in each course. In this study, we derive the most accurate estimates of the course thicknesses available by averaging the 8 sets of data mentioned earlier. The investigators whose data we have used are:

Nathaniel Davison (1765)—1 set of 205 courses, reported in (Walpole 1811: 346-347)

Sir W.M.H. Petrie-3 sets, 2 of 203 courses, 1 of 201 (Petrie 1835: Plate 8)

Julian Bruchet-1 set of 20 courses (Bruchet 1965: 30)

Georges Goyon-1 set of 201 courses (Goyon 1978: 410-413)

McKenzie-2 sets, 1 of 24 courses, 1 of 11 (McKenzie 1984)

Other data sets are available, however, they were not used in this study for one of two reasons (or both). First, there were indications that the reported thicknesses were not actually the course thicknesses at all but merely intermediate heights that when added would give the total height of the pyramid. Second, the precision of the 
data reported may not have been great enough for this study. ${ }^{1}$ The investigators whose data we have not used are:

Jacques Grobert ${ }^{2}-1$ set of 204 courses (Grobert 1801: 49-56)

Edme-Francois Jomard ${ }^{3}$-1 set of 203 courses (French Govt 1809-1822:

535-536)

Jean Marie Coutelle ${ }^{4}-1$ set of 203 courses (French Govt 1809-1822:

533-534)

Charles Piazzi Smyth ${ }^{5}$-1 set of 202 courses (Smyth 1867: 129-131)

The first indication that the course thicknesses were intended to be integer multiples of the cubit and its divisions appeared during the Data Exploration phase of the study. Figure 2 is a graph of Davison's 'processed' data (the smooth black line with peaks) showing the alignment of his data with the palm and the half palm (the vertical red lines).

Note that the very accurate alignment of the peaks with the palm does not occur because all of the stones in a course were accurately worked to the precise thickness desired-they were not. Rather, we hypothesize that a single instruction was given that a course be a certain thickness (e.g., 1 c 3 p) and then the masons would work each stone to that thickness, roughly. In aggregate, the average stone thickness would be very close to what was ordered. Thus, the perceived accuracy is actually a statistical phenomenon rather than a workmanship phenomenon.

The second thing we will show is that the thicknesses of the courses follow 3 simple patterns-(we loosely use some geological terms) Slopes, Ramps and Flats:

Slopes are characterized by a constant increment between decreasing courses.

Ramps follow a slope and also have a constant increment between decreasing courses but the increment is always smaller than the slope's increment.

Flats are characterized by a sequence of courses all having the same thickness.

\footnotetext{
${ }^{1}$ We measure precision as the average distance between adjacent possible measurements. We call this the resolution. For example, Davison records his measurements as $1 / 4^{\prime \prime}, 1 / 3^{\prime \prime}, 1 / 2^{\prime \prime}, 2 / 3^{\prime \prime}, 3 / 4^{\prime \prime}$ and even inches for a resolution of $1.0^{\prime \prime} / 6=0.17^{\prime \prime}$. Petrie's resolution is $0.1^{\prime \prime}$, Bruchet's is $0.4^{\prime \prime}$, Goyon's is $0.2^{\prime \prime}$ and McKenzie's is $0.04 "$.

${ }^{2}$ Grobert reported his figures with the ancient French pied (foot) and pouce (inch). His use of the next unit, ligne (line $=1 / 12$ pouce), is sparse. Therefore, his resolution is 1.0 pouce $\times 1.066=1.1^{\prime \prime}$, too large to be useful in this study.

${ }^{3}$ Jomard's resolution is determined as $0.55^{\prime \prime}$ by his use of the ancient French foot and liberal use of 6 lines or $0.5 \mathrm{inch}$. This is border line useful, however, Jomard was not measuring seam to seam. Of the first 19 courses, in reality, all are over 2 ancient feet. Jomard, however, shows the thickest one being $1^{\prime} 9^{\prime \prime}$. He apparently was focused on the total height of the pyramid and measuring actual course thicknesses was not his objective.

${ }^{4}$ Coutelle's resolution was $0.09^{\prime \prime}$ because he used the full spectrum of ancient lines, i.e., 1 through 11 . Unfortunately, $2 / 3$ of his courses are reported in pairs rather than singly again indicating that the total height of the pyramid was his objective rather than the individual course thicknesses.

${ }^{5}$ Smyth data is reported to $1.0^{\prime \prime}$ and so is not suitable for our study. A serious additional problem with Smyth's data is that he also reports Jomard's and Coutelle's data (Smyth 1867:314-6) and they agree quite well with his own data. They do not agree at all, however, with the original data reported by Jomard and Coutelle, themselves.
} 


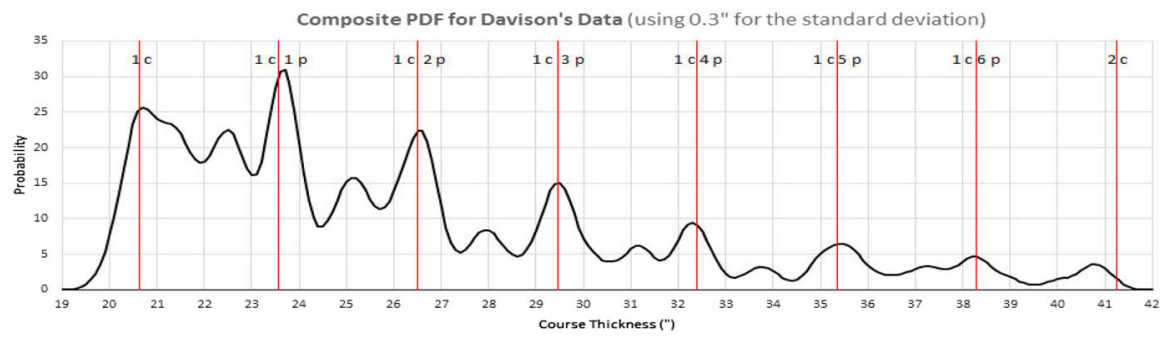

- Davison's smoothed data Palms

Fig. 2 Composite PDF of Davison's data

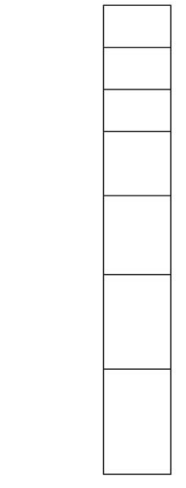

This drawing imitates the appearance of the stones. The general trend of becoming thinner as we go up is clear.

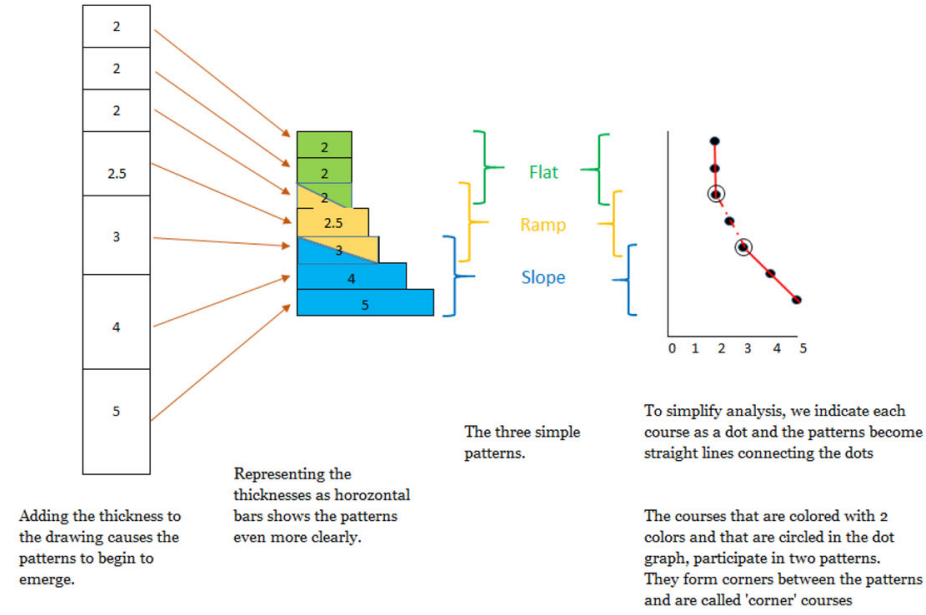

Fig. 3 How the course thicknesses and simple patterns are represented

Figure 3 below shows how the varying course thicknesses and the simple patterns are represented in this paper.

These patterns naturally divide the courses into 18 groups $^{6}$ where the lowest course of each group is one of the thick courses previously mentioned. 4 of these groups utilize just the 3 simple patterns. The other 14 groups show the use of the same three patterns along with various exceptions. Group 16, near the top of the pyramid, is one of the 4 groups which use just the slope-ramp-flat structure with no exceptions. Figure 4 shows the structure of this group. The 3 course 'slope' with increment $0.50 \mathrm{p}$, the 5 course 'ramp' with increment $0.25 \mathrm{p}$ and the 10 course 'flat' at $7.00 \mathrm{p}$ are all clearly evident.

The error bars on the points represent $95 \%$ confidence intervals $(\mathrm{CI})$ so it can be seen that the patterns are supported by the data. It would be difficult to propose an

\footnotetext{
${ }^{6}$ These 18 groups are often the same as Goyon's 19 tranches but they differ where the patterns dictate differences are appropriate. It is difficult to determine, from Goyon's paper, precisely what criteria he used to form his tranches.
} 


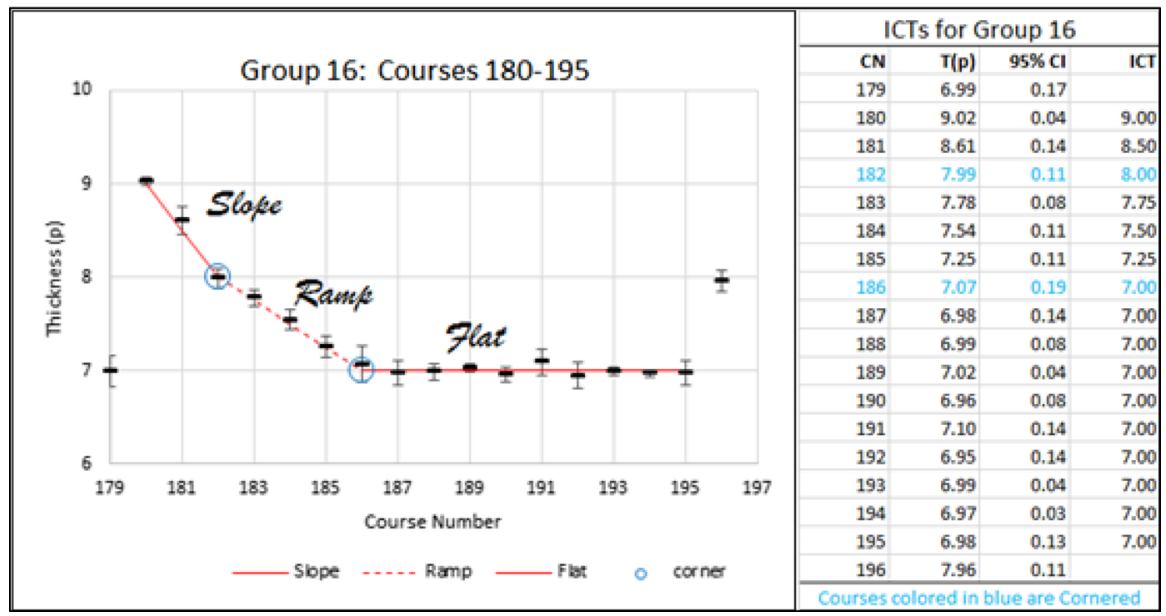

Fig. 4 The use of slope-ramp-flat in Group16

alternative interpretation of the data which honors both the $95 \%$ CIs and the use of integer multiples of the cubit and its divisions. For simplicity, we will generally use only palms rather than a mixture of palms and fingers. Thus, course 181 will be described as having a thickness of $8.50 \mathrm{p}$ rather than $8 \mathrm{p} 2 \mathrm{f}$.

These patterns are especially important because they suggest Intended Course Thicknesses (ICT) for each course that participates in a pattern. For example, in the table above, course 181 measures $8.61 \mathrm{p} \pm 0.1495 \%$ CI. Knowing that the Egyptians preferred to use integer multiples of the cubit and its divisions, we would expect that the ICT would be 8.50 p or 8.75 p. The CI supports either choice. But 181 is part of a pattern which requires us to assign it the value $8.50 \mathrm{p}$-Thus, a course can only have a definite ICT if the course belongs to a pattern. We are able to assign ICTs to 168 courses of the total 205-about $82 \%$.

The other 37 courses cannot be assigned ICTs for one of two reasons: First, they may be exception courses that do not participate in a pattern. Since they don't participate in a pattern, they cannot be assigned an ICT. There are 19 of these. Second, they may be in slopes or ramps, but the increments of the patterns are not based on the finger. We only assign ICTs that are based on the finger. These nonfinger based increments occur in groups 1 and 2 only and are discussed later. There are 18 of these courses.

From here, there are three topics we need to address:

1. Discuss what Egyptologists think about the course thicknesses now in order to establish a foundation for the contribution of this study.

2. Review how the raw data was reduced to a single set of course thicknesses upon which the patterns are based.

3. Look at all the groups to see how the three simple patterns and the exceptions that were added, were actually used by the Egyptians to construct each group. 


\section{What Egyptologists Think About the Course Thicknesses}

"Why are there so many thick courses high up in the pyramid?" Beyond this, there does not seem to be much curiosity around the courses.

The most common notion regarding the wide variety of course thicknesses is the availability of stone in the quarry. It is hypothesized that, by following a single cleavage plane, it was convenient to produce many blocks of the same thickness.

Occasionally, someone suggests that there is a correspondence between internal elements of the pyramid and the thick courses. We agree with Petrie, however, that "The position of the remarkably thick courses... do not seem to have any connection with the levels of the interior" (Petrie 1883: 184).

As a last indication of where the current thinking lies, I quote (approximately) from the Director of Antiquities with whom I had a brief conversation in 1984 when I was trying to obtain permission to take more measurements after being pulled off the GP for not having a permit. He said, "I am unaware of any outstanding questions regarding the heights of the courses of the Great Pyramid."

It is our hope that the current work will demonstrate that the course thicknesses were planned, at least at the group level, so that before starting to lay the courses of that group, all of their thicknesses were known.

\section{An Overview of the Data Reduction}

The goal of data reduction is to obtain a single value for the thickness of each course along with the smallest appropriate standard error (SE) for that value. To reach this goal, we average the various sets of data together. So an important task will be to determine how the different data sets should be weighted when taking this average.

We apply some data exploration methodologies which set the stage for understanding how to determine the variances that we use to calculate the weights. One thing that was learned during this phase is how extensively and how accurately the Royal Cubit of $20.62^{\prime \prime}$ and its divisions into 7 palms and 28 fingers was used in setting the course thicknesses.

The next step was to compare the 5 primary data sets which have thickness values for 201 courses. Here, we discover a systematic difference between Petrie and the other two primary investigators, Davison and Goyon. We believe that this systematic difference is due to a systematic error in Petrie's data and, therefore, we adjust Petrie's data.

The five primary data sets are then ready for the calculation of variances. Three independent methods are used for calculating the variances.

A critical component for two of the three methods is the three simple patterns that emerge from the realization of the use of the royal cubit. And these three patterns suggest the notion of intended course thicknesses (ICT), i.e., that the majority of courses were intended to be a precise integer number of palms and fingers. The observation of these three patterns is possible by taking unweighted averages of the five data sets. Then having made the observation of ICTs, we can use the result to 
refine our averaging of the data sets so that we not only get a refined value for the course thicknesses but we also get a refined value for their standard errors.

The three ways of estimating the variances are:

1. We calculate a standard deviation (SD) for each flat (the third simple pattern) for each data set. We average the SDs from all the flats giving us a single SD value for each data set. This measure assumes that each course in a flat is intended to be the same thickness but it does not assume any specific value for that thickness.

2. We also use the pairwise differences between datasets to estimate variances for each set. The basic model used for this calculation is that the variation of differences between two data sets is the sum of the variances of the two data sets which assumes that the two data sets are independent. This independence, of course, is not true for the actual course thicknesses, which are highly correlated, but it should be nearly true for the deviations of those thicknesses from the true values.

3. Finally, we look at the RMS deviation of a data set from the intended course thicknesses (ICT) values.

These three methods of calculating the variance produce similar results and by taking the inverse of the average of them we obtain our weights.

Figure 5 below shows the reduction of uncertainty during data reduction, starting with the raw data, then after taking a straight average and finally, after taking a weighted average.

The courses are divided into three regions because the uncertainty is different in each region. We do not know why these regions exist but, nonetheless, we set the weights, independently, within each region.

A brief explanation of what these uncertainties mean, may be useful.

First, the SD of the raw data is a statement about the stones themselves, i.e., within a single course, what variance is expected if many different blocks in the course are measured.

Second, the two standard errors (SE) tells us how close we expect a value to be to the 'true' course thickness - defined as the average of many measurements. The difference between the average straight SEs of $0.29^{\prime \prime}$ and the weighted SE of $0.24^{\prime \prime}$ is just $0.05^{\prime \prime}$ but the associated difference in the $95 \%$ confidence interval (CI) is twice that, $\pm 0.10^{\prime \prime}$, and in the $99.7 \%$ CI is three times that, $\pm 0.15^{\prime \prime}$, which are significant in our analysis.

\begin{tabular}{|l|c|c|c|c|}
\hline & \multicolumn{4}{|c|}{ Course Regions } \\
\hline Measure of Uncertainty & $1-20$ & $21-70$ & $71-201$ & $1-201$ (AlI) \\
\hline SD (") of Raw Data & 1.20 & 0.83 & 0.46 & 0.67 \\
\hline SE (") after Straight Averaging & 0.54 & 0.34 & 0.20 & 0.29 \\
\hline SE (") after Weighted Averaging & 0.46 & 0.27 & 0.17 & 0.24 \\
\hline
\end{tabular}

Fig. 5 Uncertainty in the course thicknesses 


\section{Description of the 18 Groups}

Now we will see how the patterns appear in the actual course thickness data. We describe the groups in an order that enhances the understanding of the patterns and the exceptions that were applied. We use group 16 to illustrate and discuss, in detail, the use of all three simple patterns-slopes and ramps and flats. Note that for consistency and clarity we will not be using fingers when reporting course thicknesses, i.e., we will report $7.50 \mathrm{p}$ rather than $7 \mathrm{p} 2 \mathrm{f}$.

\section{Group 16 (courses 180-195) (Refer back to Fig. 4)}

The group begins with a slope consisting of 3 courses (180-182) with thicknesses of $9.02 \mathrm{p}, 8.61 \mathrm{p}$ and $7.99 \mathrm{p}$. These are very close to $9.00 \mathrm{p}, 8.50 \mathrm{p}$ and $8.00 \mathrm{p}$, thus, we believe the increment is $0.50 \mathrm{p}$. This is followed by a ramp of 5 courses (182-186) which are very close to $8.00 \mathrm{p}, 7.75 \mathrm{p}, 7.50 \mathrm{p}, 7.25 \mathrm{p}$ and $7.00 \mathrm{p}$ with an increment of $0.25 \mathrm{p}$ between the courses, consistent with the rule that the increment of the ramp is always smaller than the increment of the slope. This is followed by a flat of 10 courses (186-195) all of which, we believe, are intended to be $1 \mathrm{c}$ or $7.00 \mathrm{p}$.

The ICTs that we assign to this group are shown on the right of the graph in Fig. 4.

There is an important feature of this group which arises from course 182 being the end of the slope as well as the beginning of the ramp. This is the most common way that adjacent patterns relate to one another. We call it 'cornering' and 182 is called a corner course. Similarly, course 186 is a corner course because it ends the ramp and begins the flat. There are 23 transitions from one simple pattern to another throughout the pyramid and only 3 of these are not cornered.

Cornering is important because it suggests intention. For example, imagine there was a four course slope with increment $1 \mathrm{p}$ and a 4 course ramp with increment $0.50 \mathrm{p}$. It is clear that care and attention is needed to form the slope and to form the ramp separately but there is no need to corner them together. This would need an additional intention beyond just stacking progressively thinner courses on top of one another.

Of the total 18 groups, 7 have the structure slope-ramp-flat. The other 11 are slope-flat (8), slope-ramp (1) and just slope (2). We include a chart in the "Appendix" at the end of this article that summarizes the properties of all 18 groups in numeric order rather than the order used here for presentation.

Of the 7 groups that have the slope-ramp-flat structure, 4 use pure simple patterns, like group 16, with no exceptions. We have already discussed group 16 so now we briefly discuss the other 3 -groups 14,8 and 13 which use pure simple patterns. We will also adopt a formulaic description of the patterns to make the structure of a group easier to understand. 


\section{Group 14 (150-161) (Fig. 6)}

The 3 course slope (150-152) has an increment of $0.50 \mathrm{p}$.

The slope is followed by a cornered 4 course ramp (152-155) with an increment of $0.25 \mathrm{p}$.

The ramp is followed by a cornered 7 course flat (155-161) with course thickness of $7.25 \mathrm{p}$.

Notice that we show on the plots the course just below the group as well as the course just above the group. For group 16, we show courses 179 and 196. For group 14 , we show courses 149 and 162. In every case, the lower course is thinner than the first course of the group and the higher course is thicker than the last course of the group. The only purpose in showing these two courses is to give perspective on the group's place between the group below it and the group above it

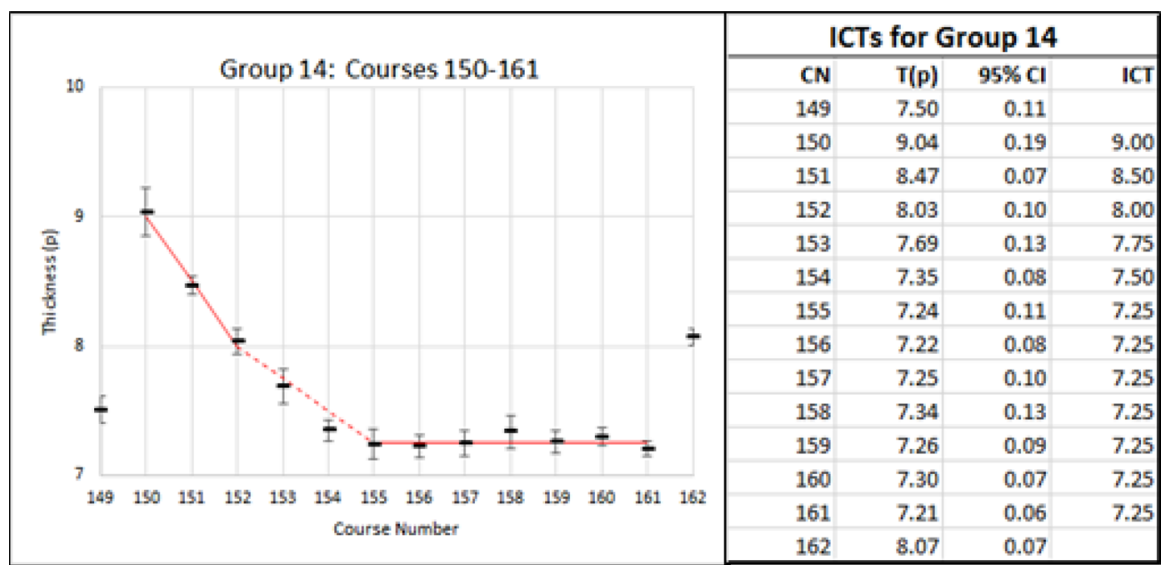

Fig. 6 The structure of Group 14

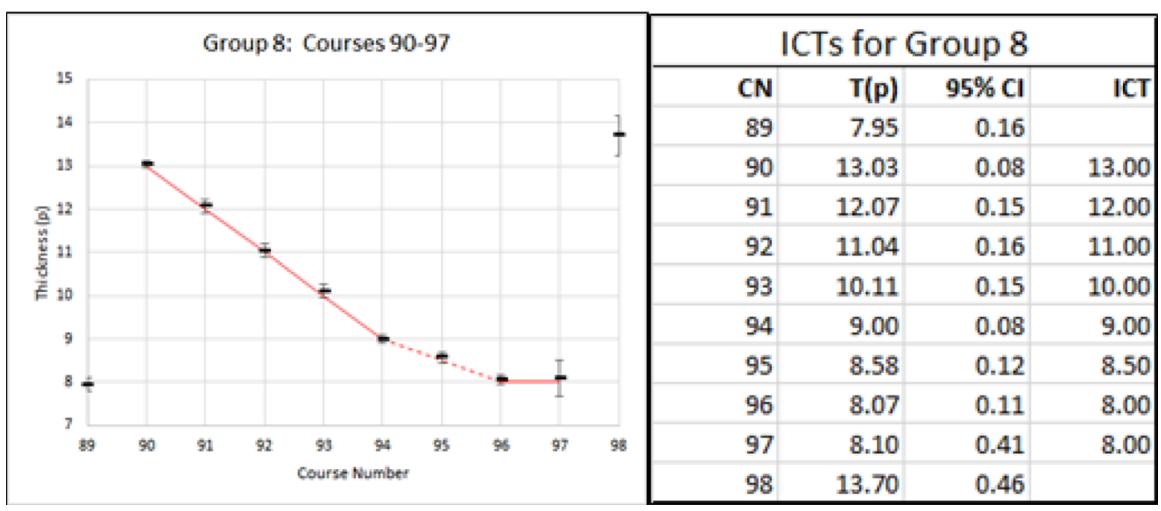

Fig. 7 The structure of Group 8 


\section{Group 8 (90-97) (Fig. 7)}

The 5 course slope (90-94) has an increment of $1.00 \mathrm{p}$.

The slope is followed by a cornered 3 course ramp (94-96) with an increment of $0.50 \mathrm{p}$.

The ramp is followed by a cornered 2 course flat (96-97) with course thickness of $8.00 \mathrm{p}$.

A flat of 2 courses does not constitute a convincing pattern but given the previous two groups, it seems reasonable to make this assignment. We will see later that there is an alternative which is to consider course 97 to be what we call an 'extra following' course and then the group would have the structure of slope-ramp. Extra courses, however, cannot be part of a pattern whereas course 97 can be, because it is $8.00 \mathrm{p}$ thick, just like 96 . The choice of a 2 course flat interpretation is made because it is deemed better for a course to be part of a pattern, if reasonable. There is one other group, 13, which has a 2 course flat which is described next.

\section{Group 13 (144-149) (Fig. 8)}

The 3 course slope (144-146) has an increment of $1.00 \mathrm{p}$.

The slope is followed by a cornered 3 course ramp (146-148) with an increment of $0.25 \mathrm{p}$.

The ramp is followed by a cornered 2 course flat (148-149) with course thickness of $7.50 \mathrm{p}$.

Now that we've discussed the 4 groups above $(16,14,8$ and 13) which follow the slope-ramp-flat structure and have no exceptions to confuse us, we can make a statistical assessment of whether these proposed patterns are supported by the data. We can make a preliminary assessment by considering outliers, i.e., courses whose $95 \%$ confidence interval does not include the Intended Course Thickness. These 4 groups, that we have just discussed, consist of 42 courses so we would expect $5 \%$, or 2 courses, to be outliers. In fact, there is 1 , course 154 in group 14 .

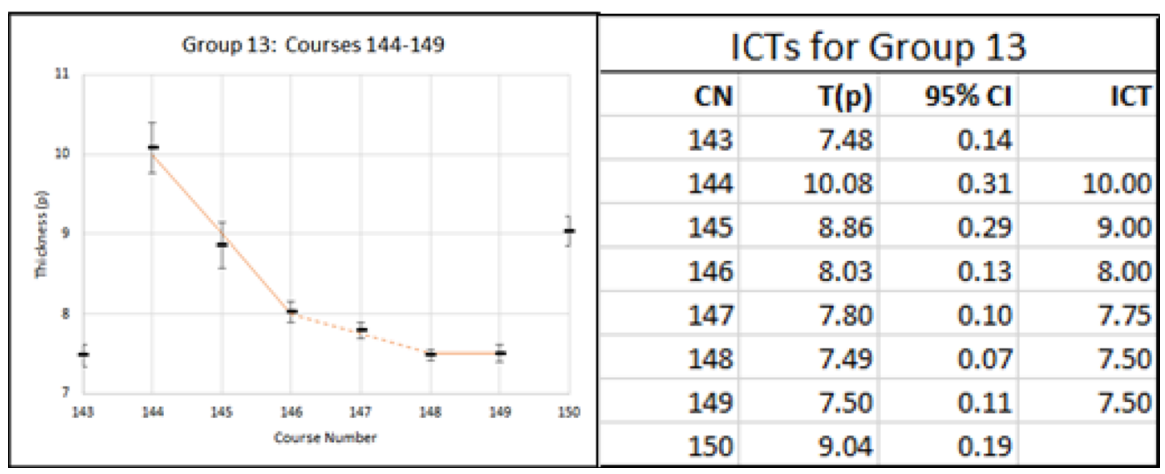

Fig. 8 The structure of Group 13 
The next group that we will discuss, group 3, is a particularly noteworthy group because course 35 , nearly 2 c 3 p thick, is the second thickest course, second only to the first course. Visually, it is prominent when looking at the Great Pyramid.

In addition, group 3 introduces our first exception, i.e., 'Extra' courses. There are two types of extra courses. The first is a 'leading' course. Leading courses are courses that start a group but that don't participate in the slope pattern that follows. These courses cannot be assigned an ICT because they do not participate in a pattern. There are 3 leading courses and all of them are larger than the first course of the slope they precede. The second type of extra course is a 'following' course. A following course is very much like a leading course in that it does not participate in nor interfere with a pattern. The difference is that following courses occur at the end of the group. There are 4 following courses -3 are larger than the previous course and 1 is smaller. All 7 extra courses appear in the lowest 6 groups.

\section{Group 3 (35-43) (Fig. 9)}

This group is unusual in that its structure consists of only a slope-there is only one other group that is just a slope, group 6.

The structure begins with an extra leading course (35).

The slope of 7 courses (36-42) has an increment of $0.75 \mathrm{p}$.

The structure ends with an extra following course (43).

One thing to note with group 3 is that 3 of the courses are outliers $(37,41$ and 42$)$ i.e., the ICTs do not lie in the $95 \%$ confidence interval. This is an unusually large number of outliers in one group. It may be that this occurs because the increment for this group is not actually $0.75 \mathrm{p}$ but rather something a little smaller. ${ }^{7}$

\begin{tabular}{|c|c|c|c|c|c|c|c|c|c|c|c|c|}
\hline \multirow{2}{*}{\multicolumn{9}{|c|}{$y=-0.6927 x+38.8$}} & \multicolumn{4}{|c|}{ ICTs for Group 3} \\
\hline & & & & & & & & $\mathrm{CN}$ & $T(p)$ & $95 \% \mathrm{Cl}$ & ICT \\
\hline 17 & \multicolumn{2}{|l|}{ \pm} & & & & & & & 34 & 8.93 & 0.09 & \\
\hline 16 & & & & & & & & & 35 & 16.83 & 0.27 & \\
\hline \multirow{5}{*}{ 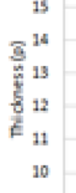 } & \multirow{2}{*}{\multicolumn{2}{|c|}{ I }} & & & & & & \multirow{2}{*}{+} & 36 & 14.19 & 0.46 & 14.00 \\
\hline & & & & & & & & & 37 & 12.94 & 0.14 & 13.25 \\
\hline & & & & & & & \multirow{2}{*}{\multicolumn{2}{|c|}{ \pm}} & 38 & 12.43 & 0.11 & 12.50 \\
\hline & & & & & & & & & 39 & 11.64 & 0.25 & 11.75 \\
\hline & & & & & & & & & 40 & 10.93 & 0.13 & 11.00 \\
\hline \multirow{2}{*}{ 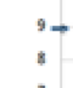 } & & & & & & & & & 41 & 10.56 & 0.22 & 10.25 \\
\hline & & & & & & & & & 42 & 9.80 & 0.25 & 9.50 \\
\hline$=$ & ss & 36 & 37 & 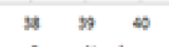 & 41 & 42 & 4 & 4 & 43 & 11.18 & 0.24 & \\
\hline & & & & Ceurse Kumber & & & & & 44 & 14.00 & 0.12 & \\
\hline
\end{tabular}

Fig. 9 The structure of Group 3

\footnotetext{
7 We can assess this by performing a linear regression of the 7 points which yields an increment of $0.693 \mathrm{p}$, an increment not based on the finger. The dotted red line in the graph represents this increment and there is only 1 outlier, course 37 . We will come back to this, after we consider groups 1 and 2 which have unequivocal non-finger based increments. Interesting that this non-finger based increment issue only appears in the lower 3 groups.
} 


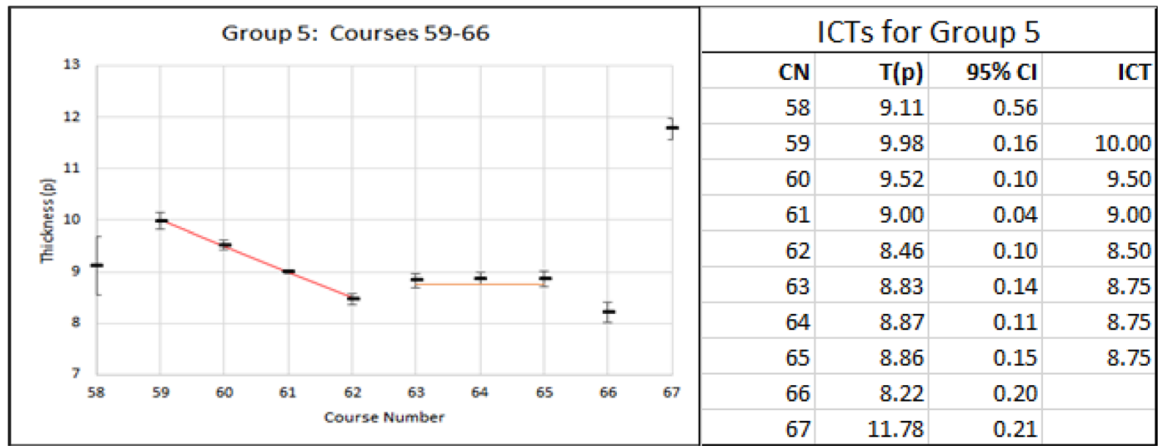

Fig. 10 The structure of Group 5

We have mentioned before un-cornered transitions. The next group, group 5 is one of the three groups with this feature-the other 2 are groups 17 and 4 .

\section{Group 5 (59-66) (Fig. 10)}

The 4 course slope (59-62) has an increment $0.50 \mathrm{p}$.

The slope is followed by an un-cornered 3 course flat (63-65) at $8.75 \mathrm{p}$.

The structure ends with an extra following course (66).

This is the only extra following course (of a total of four) whose thickness is smaller than the courses that precede it.

The 3 course flat (63-65) is listed as being $8.75 \mathrm{p}$ because integer use of fingers is the most common. In this case, however, half integer use of fingers may be involved or $8.88 \mathrm{p}$. We can return to this issue later.

The next group introduces another exception we call an 'inserted' course. An inserted course is a course that interrupts an otherwise straightforward pattern. If the course is removed the simple pattern becomes clearly evident. In the whole pyramid, there are 6 inserted courses, three have been inserted into slopes and three have been inserted into flats. No courses have been inserted into ramp patterns. Since an inserted course does not participate in any pattern we cannot assign an ICT to it.

\section{Group 15 (162-179) (Fig. 11)}

The 5 course slope $(162-163,165-166)$ has an increment of $0.25 \mathrm{p}$.

The slope has an inserted course (164).

The slope is followed by a cornered 13 course flat (167-179) at $7.00 \mathrm{p}$.

Just to clarify the action of an inserted course, we can de-insert it and move it to the end of the structure and let it be an extra following course. The result is shown in Fig. 12.

The next group provides our first example of a 'double flat' i.e., two consecutive flats. There are 15 flats in total and 7 of them are double while the other 8 are regular or single. In a double flat, the thickness of courses in the second flat is always less than the thickness of the courses in the first flat. Of the 7 double flats -4 have a 


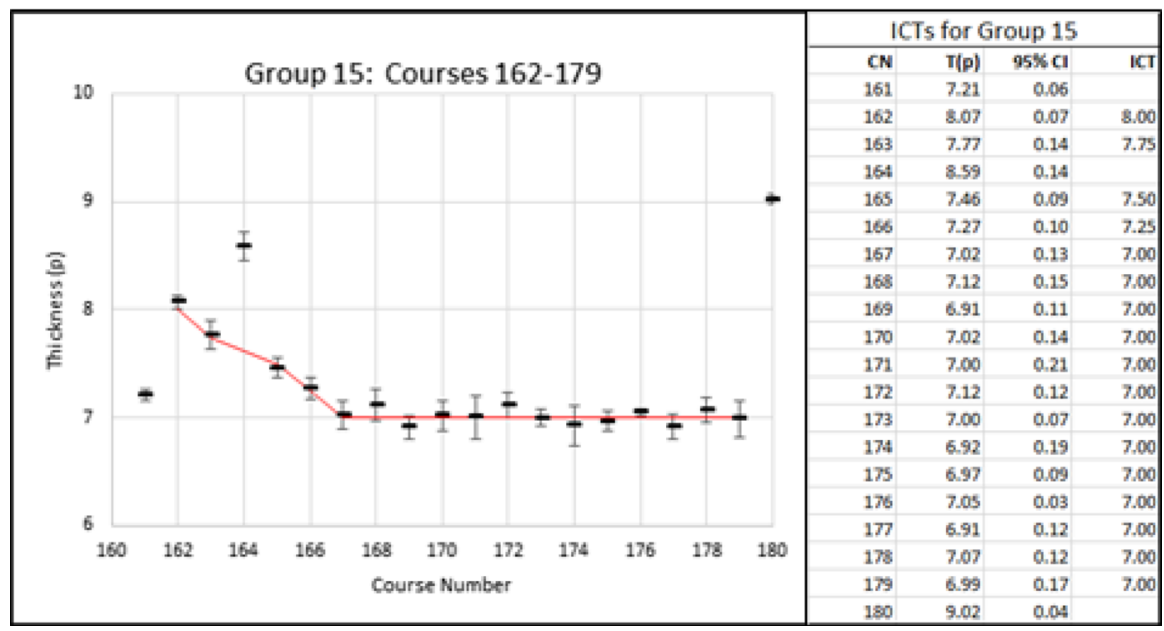

Fig. 11 The structure of Group 15

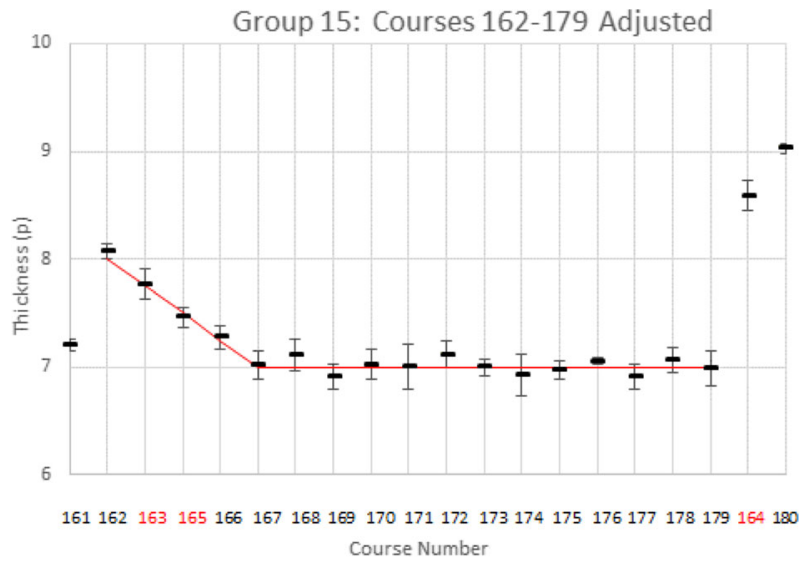

Fig. 12 The structure of Group 15 after adjustment

difference in thickness between the two flats of $0.25 \mathrm{p}$, the other 3 have a difference of $0.50 \mathrm{p}$.

\section{Group 10 (108-117) (Fig. 13)}

The 3 course slope (108-110) has an increment of $1 \mathrm{p}$.

The slope is followed by a cornered 7 course double flat. The first flat has 4 courses (110-113) at $8.00 \mathrm{p}$. The second flat has 3 courses at $7.75 \mathrm{p}$. Notice that a second flat can never be cornered with the first flat.

The second flat has an inserted course, 116. 


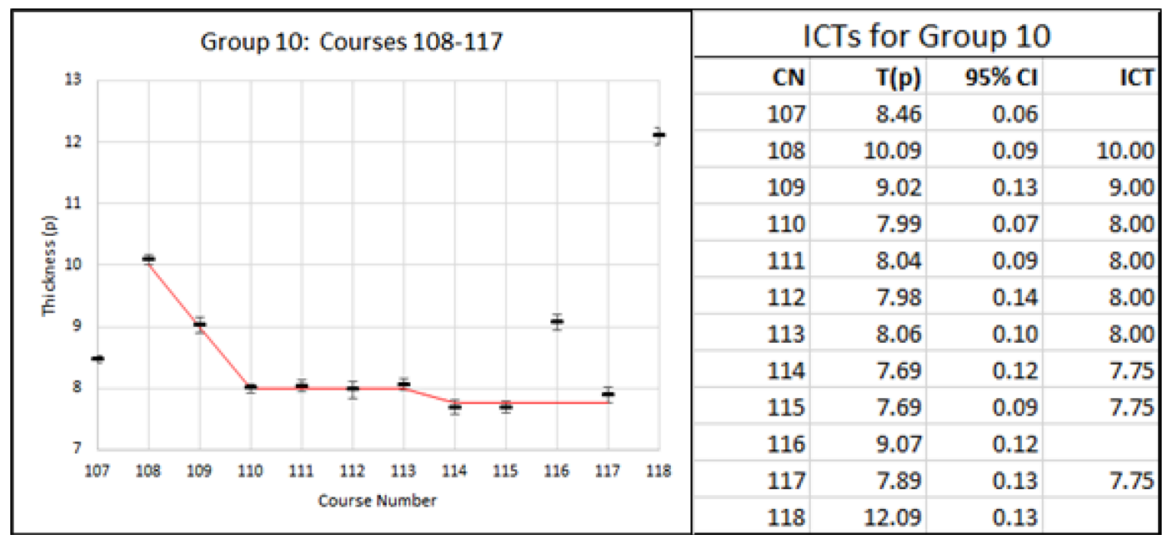

Fig. 13 The structure of Group 10

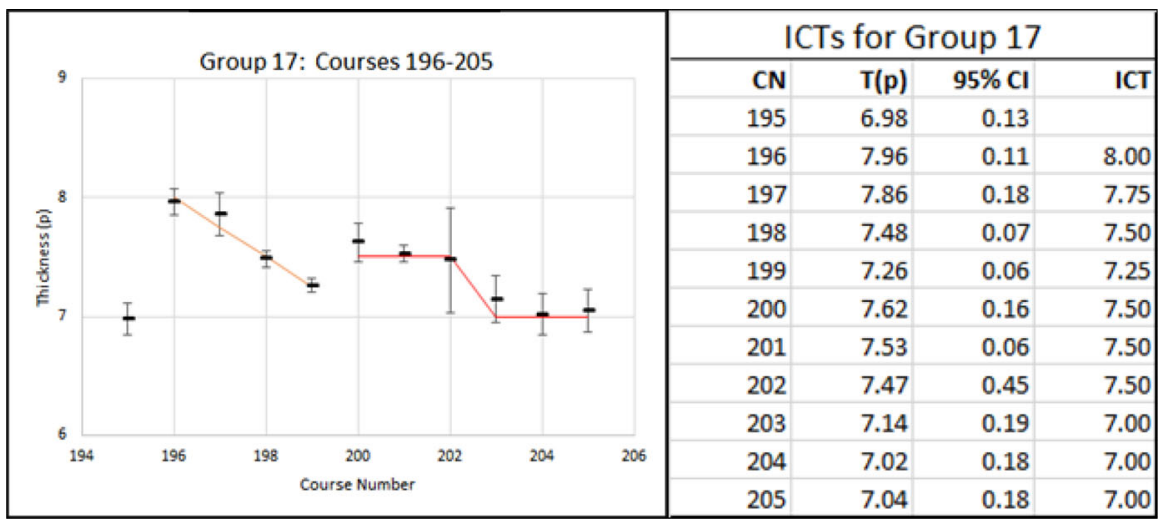

Fig. 14 The structure of Group 17

\section{Group 17 (196-205) (Fig. 14)}

This group is at the top of the extant pyramid (i.e., at the time of Davison, 1765).

The 4 course slope (196-199) has an increment $0.25 \mathrm{p}$.

The slope is followed by an un-cornered doubled flat of 6 courses, 3 (200-202) at $7.50 \mathrm{p}$ and $3(203-205)$ at $7.00 \mathrm{p}$.

\section{Group 4 (44-58) (Fig. 15)}

The 4 course slope (44-45, 47 and 49) has an increment of $1.00 \mathrm{p}$.

The slope is interrupted by two inserted courses $(46,48)$.

The slope is followed by an un-cornered ramp of 4 courses (50-53) with increment of $0.25 \mathrm{p}$.

The ramp is followed by a cornered double flat of 5 courses, 3 (53-55) at $8.75 \mathrm{p}$ and $2(56-57)$ at $8.25 \mathrm{p}$. 


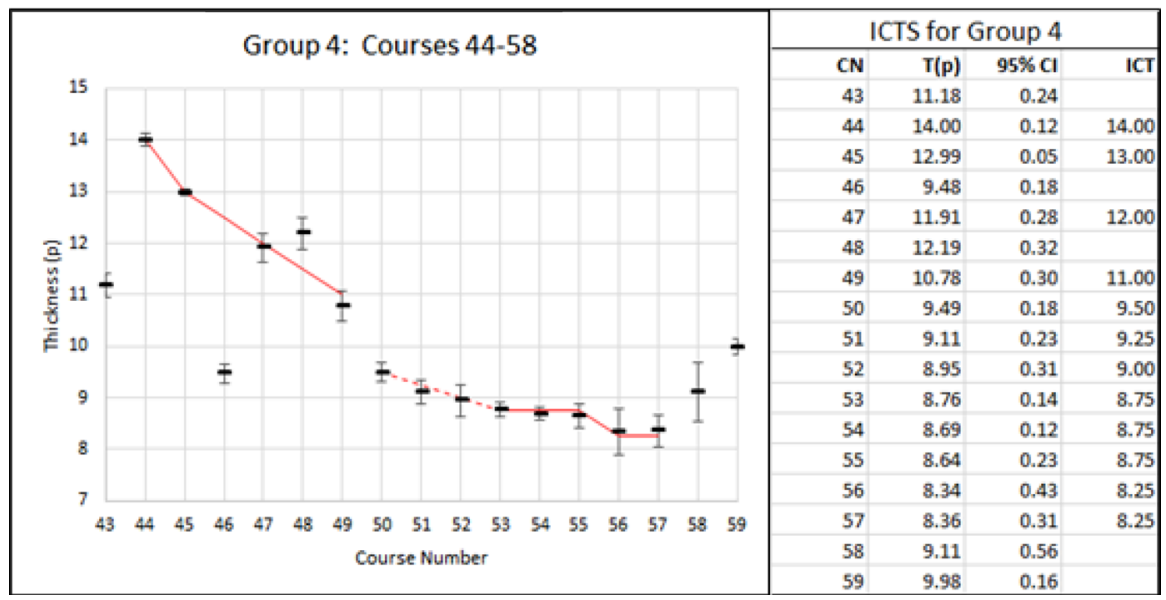

Fig. 15 The structure of Group 4

Group 4: Courses 44-58 Adjusted

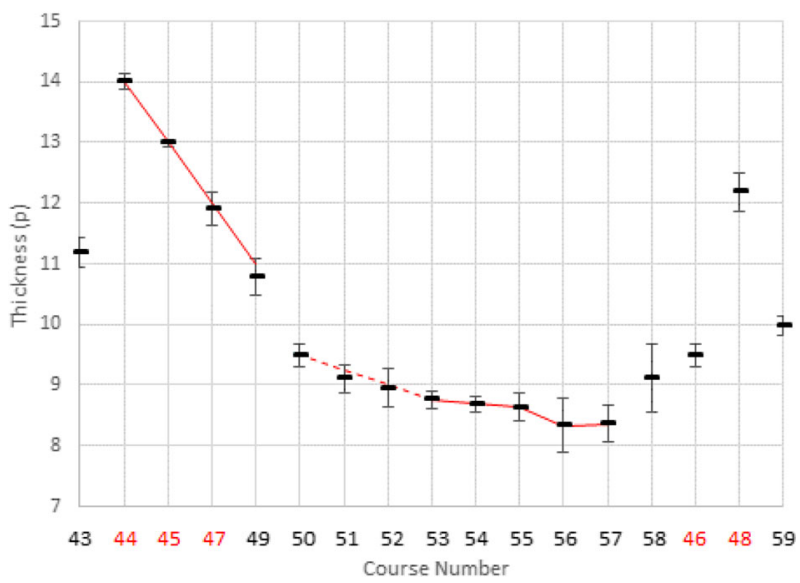

Fig. 16 The structure of Group 4 after Adjustment

The structure ends with an extra following course (58).

Just to clarify the underlying group structure, we move the inserted courses (46 and 48) over to become additional extra following courses and we get Fig. 16.

\section{Group 7 (74-89) (Fig. 17)}

Group 7 has a unique element which appears in no other group, that we call 'missing courses' in the slope. The opposite of inserted courses, a missing course is one that is needed to properly complete the simple pattern. There are 2 missing courses between course 75 and course 76 . Since the increment of the slope is $0.50 \mathrm{p}$ they 


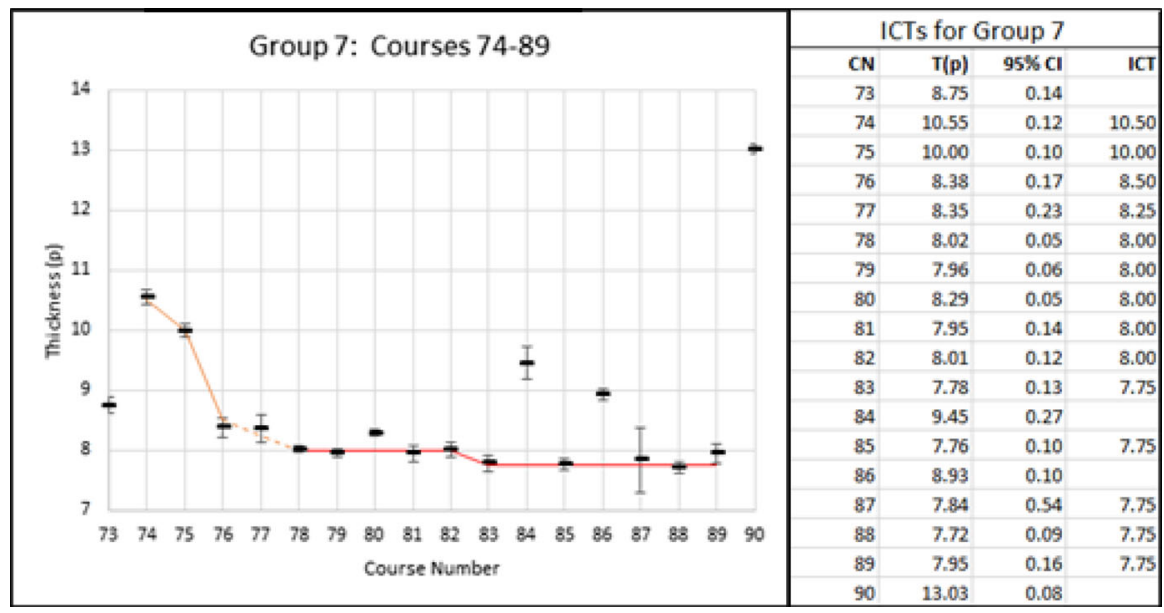

Fig. 17 The structure of Group 7

would need to be $9.50 \mathrm{p}$ and $9.00 \mathrm{p}$ thick to complete the slope pattern properly. Since there are only 3 courses in this slope, it may seem arbitrary to postulate 2 missing courses. The only reason that we do this, is because, remarkably, exactly these two courses have been inserted into the second flat in the correct order, i.e., courses 84 and 86 .

The 3 course (74-76) slope has an increment of $0.50 \mathrm{p}$.

The slope has two missing courses between 75 and 76 .

The slope is followed by a cornered 3 course (76-78) ramp with increment $0.25 \mathrm{p}$.

The ramp is followed by a cornered 10 course double flat. The first flat of 5 courses (78-82) is $8.00 \mathrm{p}$ and the second flat of 5 courses $(83,85,87-89)$ is $7.75 \mathrm{p}$.

The second flat is interrupted by the two inserted courses $(84,86)$ noted earlier.

We can adjust this structure by moving the inserted courses to where the missing courses are supposed to be. Figure 18 below shows how the structure would look after this adjustment.

There may be a question about why course 80 is considered to be part of the first flat since statistically it appears quite unlikely. The reason is that when the 5 sets of data were averaged the SE for this course was only $0.15^{\prime \prime}$, the smallest in the group and one of the 15 smallest in the whole pyramid. Such a small SE may not provide an accurate picture of the true course variability and as a result may underestimate the $95 \%$ confidence interval.

The next two groups that we will discuss are groups 1 and 2, i.e., the lowest two groups. They share the property that the increments of their slopes are not integral multiples of a finger. We refer to this as 'non-finger based increments'. In addition, they both have two adjacent 'adjusted' courses within their slopes.

Adjusted courses, unlike inserted courses, do not interfere with a pattern, rather they seem to have been adjusted so that they no longer are a part of the pattern. For example in $10 \mathrm{p}, 9 \mathrm{p}, 11 \mathrm{p}, 8 \mathrm{p}$, the $11 \mathrm{p}$ course has been inserted into the pattern-it breaks up or disrupts the pattern and has to be removed to clarify the pattern. But in 


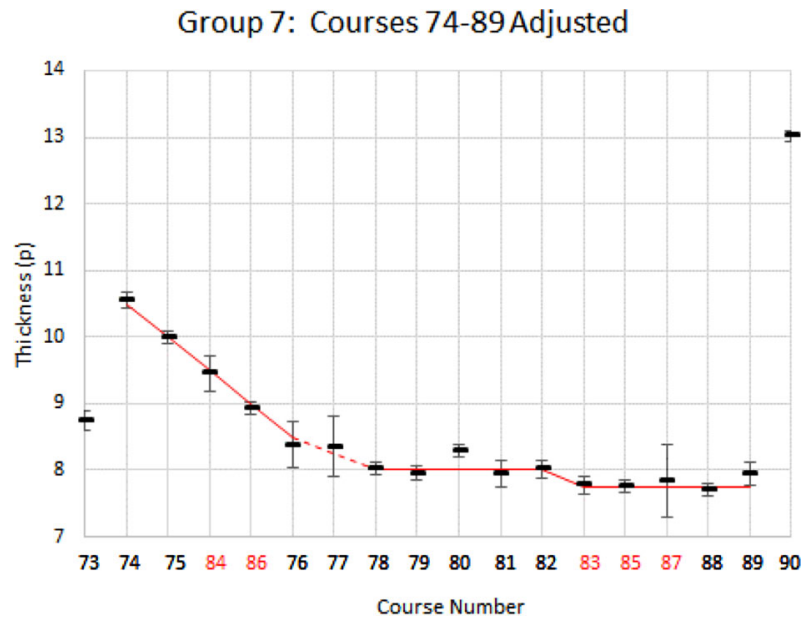

Fig. 18 The structure of Group 7 after Adjustment

$10 \mathrm{p}, 9 \mathrm{p}, 11 \mathrm{p}, 7 \mathrm{p}$, the $11 \mathrm{p}$ course has not been inserted, rather it can be viewed as having been adjusted upwards from $8 \mathrm{p}$ by $3 \mathrm{p}$ to $11 \mathrm{p}$. The pattern will be disrupted if the course is removed, whereas re-adjusting the course by subtracting $3 \mathrm{p}$ will complete the pattern. Adjusted courses appear in pairs of 2 adjacent courses and the same adjustment is made to both courses in the pair. In group 1, the adjustment was to subtract about $1.35 \mathrm{p}$ from each of the two courses. Groups 1 and 2 are the only groups that definitely have adjusted courses. 12a (to be discussed) may also have a pair of adjusted courses.

\section{Group 1 (1-18) (Fig. 19)}

An extra leading course, 1 , starts the structure.

The 10 course slope $(2-4,7-13)$ has a non-finger based increment of around $0.611 \mathrm{p}$.

In the slope, courses 5 and 6 have been adjusted downward by about $1.35 \mathrm{p}$.

The slope is followed by an 'approximately cornered ${ }^{8} 5$ course doubled flat -3 courses (13-15) at $10.00 \mathrm{p}$ and 2 courses (16-17) at $9.75 \mathrm{p}$.

1 extra following course, 18 , completes the structure.

Now we address the increment in the slope not being based on the finger. Clearly, the courses between 2 and 13 (excepting 5 and 6) lie close to a line indicating a constant increment and when we regress those points we get a slope increment of $0.611 \mathrm{p} \pm 0.026$. Figure 20 below shows what the increment would be for the conventional increments that we have seen in other groups.

The $\mathrm{p}$ value (probability or percentile value, not palm value) for $0.611 \mathrm{p} \pm 0.026$ to be consistent with $0.50 \mathrm{p}$ is $0.002 \%$ and that for $0.75 \mathrm{p}$ is less than $0.001 \%$.

\footnotetext{
8 The flat is 'approximately cornered' because the non-finger increment of the slope may lead to a course thickness for the last slope course which is not exactly the same as the flat thickness.
} 


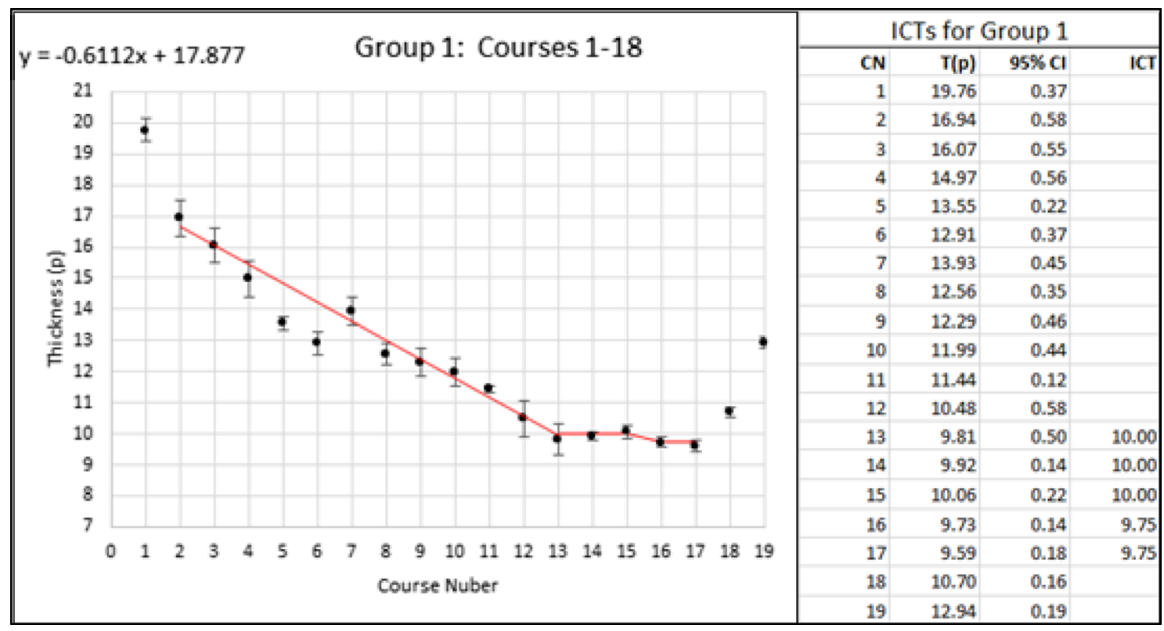

Fig. 19 The structure of Group 1

Fig. 20 Slopes for different increments

\begin{tabular}{|c|c|}
\hline Increment & Slope \\
\hline $1.00 p=4 f$ & 1.00 \\
\hline $0.75 p=3 f$ & 0.75 \\
\hline $0.50 p=2 f$ & 0.50 \\
\hline $0.25 p=1 f$ & 0.25 \\
\hline
\end{tabular}

These probabilities are so small that the increment $0.611 \mathrm{p}$ is deemed unique from either $0.50 \mathrm{p}$ or $0.75 \mathrm{p}$. The question then is, "What is the basis of this increment?" We will look at group 2 next, and its increment, to get additional information on this question. Note that we do not assign ICTs to these courses.

\section{Group 2 (19-34) (Fig. 21)}

The 10 course slope $(19,22-30)$ has a non-finger increment of about $0.316 \mathrm{p}$.

The slope has two adjusted courses $(20,21)$ that have been adjusted downward by about $4.30 \mathrm{p}$ from where the slope pattern would indicate.

The slope is followed by an approximately cornered 5 course, double flat, 2 courses (30-31) at $9.50 \mathrm{p}$ and 3 courses (32-34) at $9.00 \mathrm{p}$.

We regress courses 19, 22-30 for the non-finger increment and obtain 0.316 p \pm 0.015. In Fig. 22 below, we plot the two non-finger increments (i.e., from groups 1 and 2) with their $99.7 \%$ confidence intervals ( $\pm 3 \mathrm{SE}$ ) showing how neither one is likely to have the finger as it basis. The black horizontal lines indicate fingers, $0.75=3 \mathrm{f}, 0.50=2 \mathrm{f}$ and $0.25=1 \mathrm{f}$.

We know that the Egyptians used integer multiples of cubits, palms and fingers as well as 2/3 and 1/3 of a cubit (Gillings 1972: 219), (Rossi 2003: 117 and 167). 


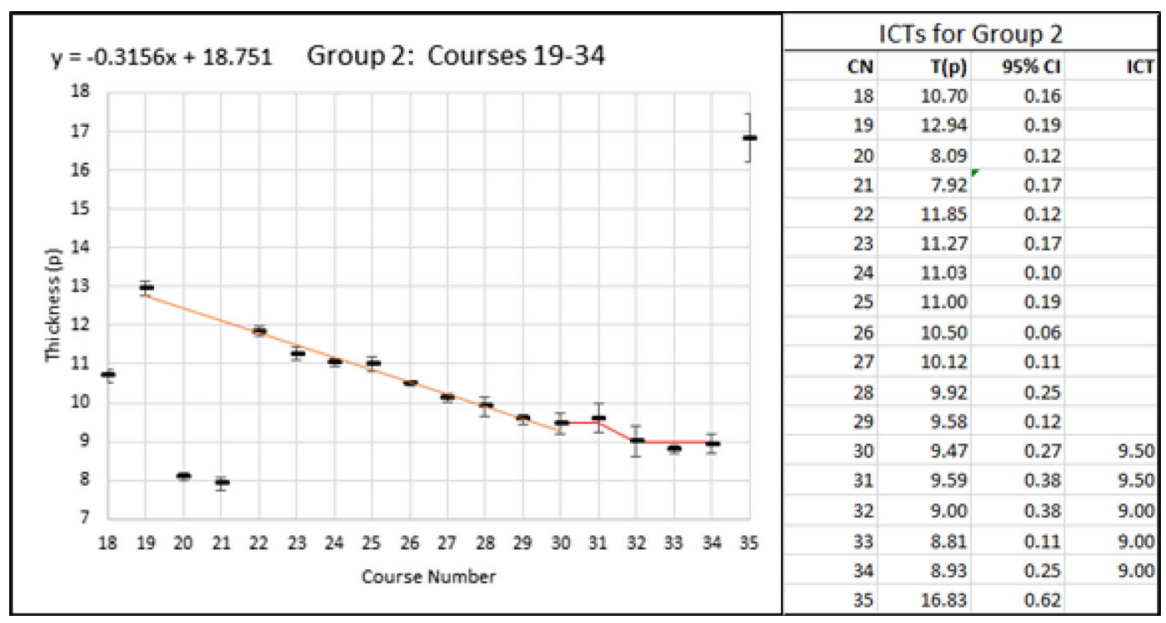

Fig. 21 The structure of Group 2

Fig. 22 Non-finger increments

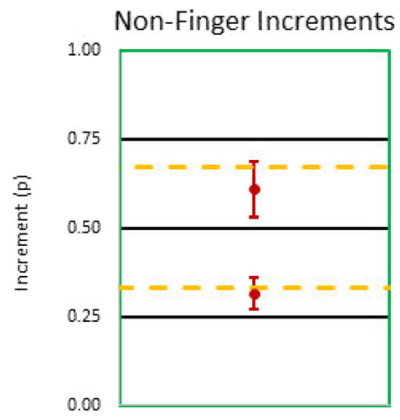

Extrapolating down to the palm, we conjecture that our non-finger increments could be $2 / 3$ and $1 / 3$ of a palm shown by the orange horizontal, dashed lines. With this discussion, we are only trying to establish that these two non-digit increments are real and that there is a likelihood that they were selected intentionally. We are addressing these increments along with the possible non-finger increment in group 3 , in a study outside the scope of this article.

As an interesting aside, Petrie noted that course 19 (in group 2) aligned very closely with the entrance passage where they would meet the surface of the pyramid as shown in Fig. 23 below (Petrie 1883: plate XI).

Using our own data along with data from Petrie (Petrie 1883: 42 and 52), we get a slant height on the face of the casing blocks for course 19 of $16.46 \mathrm{p}$ and for the entrance passage of $16.38 \mathrm{p}$, only $0.08 \mathrm{p}$ different. He explains further, "After seeing the entrances of the Third Pyramid, the South Pyramid of Dahsur and the Pyramid of Medum, all of which retain their casing, there seemed scarcely a question but that the rule was for the doorway of a Pyramid to occupy the height of 
exactly one or two courses on the outside." (Petrie 1883: 51). Then he comments on courses 20 and 21, "There are two unusually small courses next over this... The explanation of this is clear, if the doorway came out in the 19th course; an unusually thick lintel course was needed, so two thinner courses were put in, that they might be united for obtaining extra thickness..." (Petrie 1883: 52). This topic has been included because this is the most convincing case of any relationship between a course and the interior of the pyramid.

The next group introduces a 'doubled ramp'. To illustrate a doubled ramp, consider a conventional ramp of 3 courses, 10 p, 9 p, and 8 p. A doubled ramp would have 6 courses, 10 p, 10 p, 9 p, 9 p, 8 p and 8 p.

\section{Group 11 (118-129) (Fig. 24)}

The 3 course slope (118-120) has an increment of $1.00 \mathrm{p}$

Fig. 23 Alignment between the entrance passage and Course 19

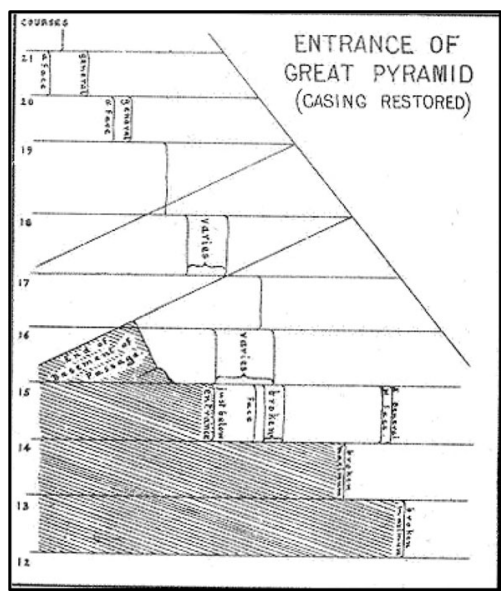

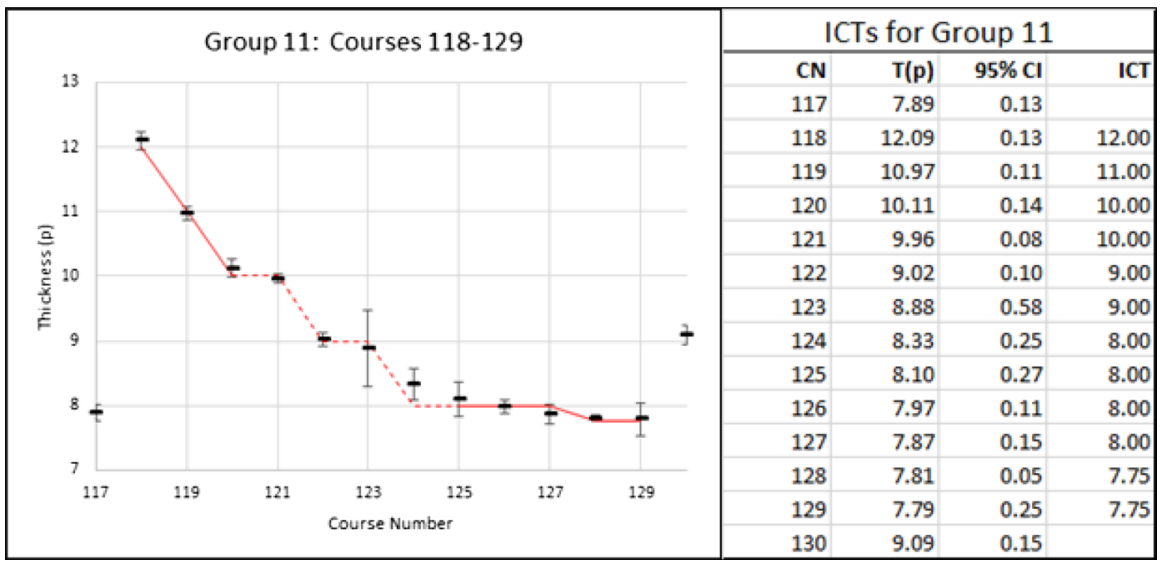

Fig. 24 The structure of Group 11 
The slope is followed by a cornered, 6 course doubled ramp (120-125) with increment of $1.00 \mathrm{p}$.

The doubled ramp is followed by a cornered 5 course doubled flat, 3 courses (125-127) at $8.00 \mathrm{p}$ and 2 courses (128-129) at $7.75 \mathrm{p}$.

Notice that this structure appears to violate the rule that the increment for a ramp is always less than the increment of the slope. In this case, both increments are $1.00 \mathrm{p}$. We rationalize this violation away by noting that, because of the doubling, the increment of the ramp is effectively $0.50 \mathrm{p}$ and, as a result, honors the rule

The appearance of courses 124-128 as a decreasing sequence with an increment of $1 / 2 \mathrm{f}$ suggests an alternative interpretation of this group which we do not consider further here, however, it will be kept in mind as further work is done.

The next two groups use a modification of doubling that we call a 'doubled tapered' ramp (or slope). A tapered ramp would be $10 \mathrm{p}, 9 \mathrm{p}$ and $8.5 \mathrm{p}$. It is called tapered because the increments decrease by a half. In this example, $1 \mathrm{p}$ is the first increment and $0.5 \mathrm{p}$ is the second increment. A doubled tapered ramp would be 10 p, 10 p, 9 p, 9 p, 8.5 p and 8.5 p.

\section{Group 9 (98-107) (Fig. 25)}

The 5 course slope (98-102) has a 1.00 p increment.

The slope is followed by a cornered doubled tapered ramp (102-107) with increments $1.00 \mathrm{p}$ and $0.50 \mathrm{p}$.

The doubled tapered ramp may seem to be a bit artificial but exactly the same pattern is also used in group 6's slope below.

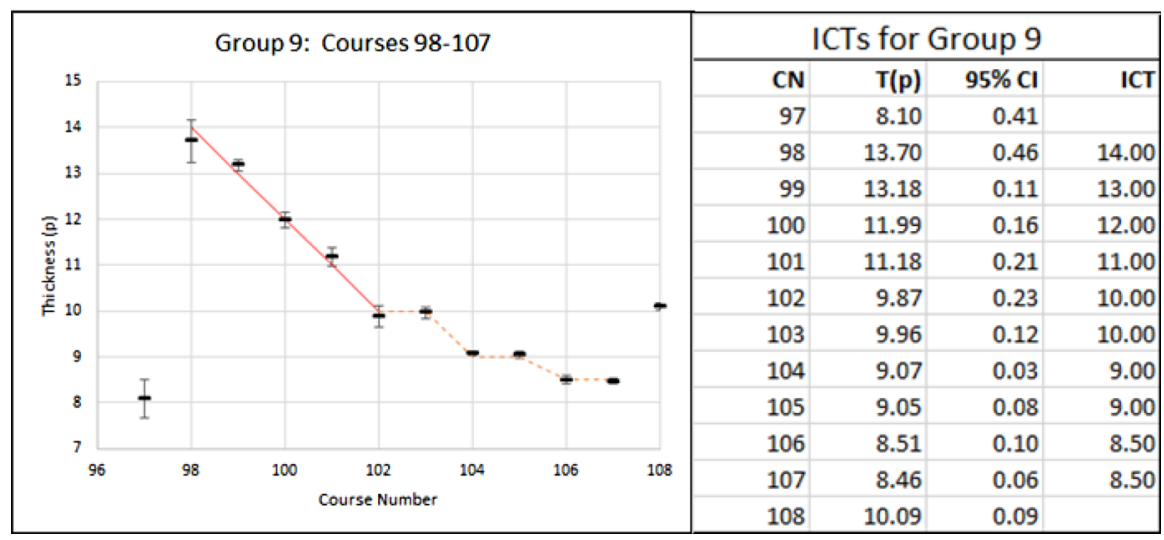

Fig. 25 The structure of Group 9 


\begin{tabular}{|c|c|c|c|c|c|c|c|c|c|c|}
\hline & & & 6: Courses 67-7 & & & & & Is for & roup 6 & \\
\hline 13 & & & & & & & $\mathrm{CN}$ & $T(p)$ & $95 \% \mathrm{Cl}$ & ICT \\
\hline 12 & $I$ & & & & & & 66 & 8.22 & 0.20 & \\
\hline${ }_{11}$ & & & & & & & 67 & 11.78 & 0.21 & \\
\hline$\frac{\bar{a}}{\bar{b}}$ & & I & & & & $=$ & 68 & 10.67 & 0.27 & 10.75 \\
\hline$\frac{\tilde{y}^{3}}{10}$ & & & & & & & 69 & 10.81 & 0.28 & 10.75 \\
\hline$F_{9}$ & & & & & $=$ & & 70 & 9.59 & 0.44 & 9.50 \\
\hline 8 & & & & & & & 71 & 9.58 & 0.13 & 9.50 \\
\hline 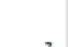 & & & & & & & 72 & 8.94 & 0.11 & 8.88 \\
\hline 6 & 67 & 68 & 69 & 72 & 7 & 74 & 73 & 8.75 & 0.14 & 8.88 \\
\hline & & & umber & & & & 74 & 10.55 & 0.12 & \\
\hline
\end{tabular}

Fig. 26 The structure of Group 6

\section{Group 6 (67-73) (Fig. 26)}

The structure begins with an extra leading course, 67.

The doubled-tapered slope (68-73) has increments of $1.25 \mathrm{p}$ (or $5 \mathrm{f}$ ) and $0.625 \mathrm{p}$ (or $2.5 \mathrm{f})$. The actual course thicknesses are $2 @ 10.75 \mathrm{p}, 2 @ 9.50 \mathrm{p}$ and $2 @ 8.88 \mathrm{p}$.

It is interesting to note that when the straight averages were being used, this group could also have been interpreted as just a doubled slope. The thicknesses would have been $10.75 \mathrm{p}, 9.75 \mathrm{p}$ and $8.75 \mathrm{p}$. Once we had performed the weighted averages, however, the $95 \%$ confidence intervals shrunk sufficiently so that the doubled-tapered slope proposal emerges as much more likely.

The only courses left (130-143) are the most difficult courses to interpret. Three different structures are proposed that might be used to 'understand' these courses, however, none of the proposals are totally satisfactory. The first one is to use two groups, 12a and 12b. The other two, 12\#1 and 12\#2, put all 14 courses into one group.

\section{Groups 12a (130-137) and 12b (138-143) (Fig. 27)}

The first possible structure involves breaking these courses up into two groups.

\section{The first group, 12a (130-137):}

The 4 course slope (130-133) has a $0.50 \mathrm{p}$ increment.

The slope is followed by a cornered 3 course flat (133-135) at $7.50 \mathrm{p}$.

Two adjacent adjusted courses (136 and 137) ${ }^{9}$ complete the structure

\section{The second group, 12b, (138-143):}

The 3 course slope (138-140) has a 0.75 p increment.

The slope is followed by a cornered 4 course flat (140-143) at $7.50 \mathrm{p}$.

There are two problems with this proposal: First, regarding 12a, the only other two adjusted pairs appear low in groups, i.e., 1 and 2, as mentioned before and, in addition, those other adjusted pairs appear in slopes not flats. Second, regarding $12 \mathrm{~b}$,

\footnotetext{
9 The adjustment is either being increased by $0.25 \mathrm{p}$ or by $0.50 \mathrm{p}$ - either interpretation is supported by the data.
} 


\begin{tabular}{|r|r|r|r|r|r|r|r|r|}
\hline \multicolumn{3}{|c|}{ Group 12a: Courses 130-137 } & \multicolumn{3}{|c|}{ Group 12b: Courses 138-143 } \\
\hline & & & & & & & \\
\hline
\end{tabular}

Fig. 27 The structure of Groups $12 \mathrm{a} \& 12 \mathrm{~b}$

course 139 is not positioned well to be part of the proposed 3 course slope. Its $\mathrm{p}$ value relative to $8.25 \mathrm{p}$ is less than $0.001 \%$, i.e., quite unlikely. In addition, course 141 is not positioned well to participate in the flat either with a $p$ value of $0.002 \%$-this latter fact, however, actually plagues all three interpretations.

\section{Group 12 \#1 (130-143) (Fig. 28)}

The second possible structure treats all the courses as one group.

The slope of 4 courses (130-133) has an increment of $0.50 \mathrm{p}$.

The slope is followed by a cornered 7 course flat $(133-135,140-143)$ at $7.50 \mathrm{p}$.

The 4 courses, 136-139, are interpreted as inserted courses.

A problem is that no other group has more than 2 inserted courses and none of those have the courses adjacent to one another.

\section{Group 12 \#2 (130-143) (Fig. 29)}

The third possible structure also groups courses 130-143 into one group.

The 4 course slope (130-133) has an increment of $0.50 \mathrm{p}$. 


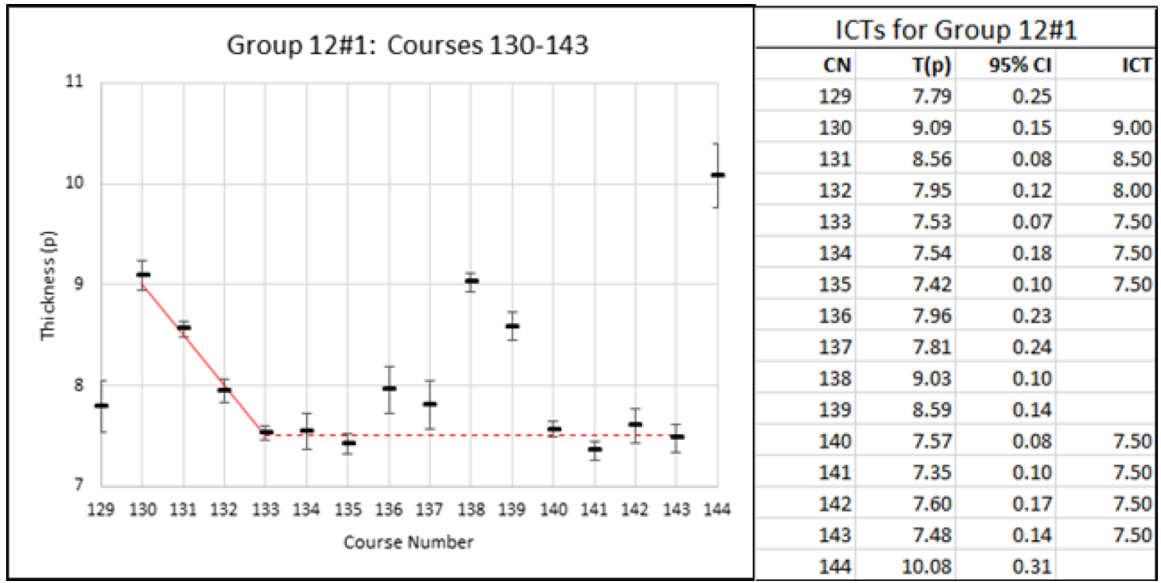

Fig. 28 The structure of Group 12 \#1

Group 12\#2: Courses 130-143

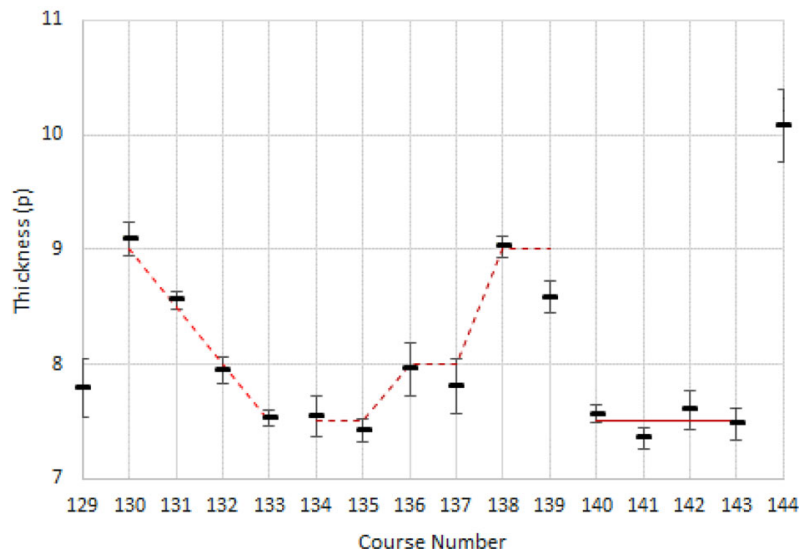

Fig. 29 The structure of Group 12 \#2

The slope is followed by a 6 course (134-139) 'inverse, ${ }^{10}$ double-tapered ramp with first increment $0.50 \mathrm{p}$ and the second increment $1.00 \mathrm{p}$.

The ramp is followed by an un-cornered 4 course flat (140-143) at $7.50 \mathrm{p}$.

The main problem with this alternative is that no other group has an inverse doubled tapered ramp so it seems somewhat contrived to call it a pattern. Ameliorating this problem, somewhat, is the presence of two groups having the doubled tapered slope or ramp, i.e., groups 6 and 9, and a third group, 11, with a doubled ramp. Another problem with this alternative is that the $\mathrm{p}$ value for course 139 relative to $9.00 \mathrm{p}$ is less than $0.001 \%$, quite unlikely.

At this time, we choose to interpret the courses as 2 groups, 12a and 12b. We make this choice because, even though there are concerns, this interpretation seems

\footnotetext{
${ }^{10}$ This is called inverse because the courses get thicker rather than thinner as we go up.
} 
to be the simplest involving the fewest 'unique' features. We note that we are open to change as we learn more.

\section{Conclusions}

The cubit, palm and finger were used in setting the thicknesses of the courses. Three simple patterns-slopes, ramps and flats-were also used when setting the thicknesses along with a number of exceptions. We do not understand why this was done only that it was. It does suggest, though, that a higher level of intention was exercised during the design process than was previously thought. It also suggests that the builders would have to have had a "large scale management plan of the building site" (C. Rossi, personal communication).

\section{Appendix}

See Fig. 30.

\begin{tabular}{|c|c|c|c|c|c|c|c|c|c|c|c|c|c|c|}
\hline \multicolumn{3}{|c|}{ In Height Order } & \multirow[b]{2}{*}{$L^{ \pm}$} & \multicolumn{4}{|c|}{ Slopes } & \multicolumn{3}{|c|}{ Ramps } & \multicolumn{3}{|c|}{ Flats } & \multirow[b]{2}{*}{$F^{*}$} \\
\hline Group\# & Start & End & & $\#$ & Start(p) & Incr.(p) & $\mathrm{N} / \mathrm{A} / \mathrm{M}^{*}$ & $\#^{ \pm: *}$ & Start(p) & Incr.(p) & $\#^{* * *}$ & Size(p) & $\mathrm{N}^{*}$ & \\
\hline 1 & 1 & 18 & IL & 10 & 17 & 0.611 & $2 A S$ & & & & $3 / 2$ & $10.00 / 9.75$ & & $1 \mathrm{~F}$ \\
\hline 2 & 19 & 34 & & 11 & 13 & 0.319 & 2As & & & & $2 / 3$ & $9.50 / 9.00$ & & \\
\hline 3 & 35 & 43 & 1L & 7 & 14 & 0.75 & & & & & & & & $1 \mathrm{~F}$ \\
\hline 4 & 44 & 58 & & 4 & 14 & 1.00 & $2 \mathrm{Ns}$ & 4 & 9.5 & 0.25 & $3 / 2$ & $8.75 / 8.25$ & & $1 \mathrm{~F}$ \\
\hline 5 & 59 & 66 & & 4 & 10 & 0.50 & & & & & 3 & 8.75 & & $1 \mathrm{~F}$ \\
\hline 6 & 67 & 73 & 1L & 6 & $10.75 \mathrm{D}$ & $1.25 / 0.62$ & & & & & & & & \\
\hline 7 & 74 & 89 & & 3 & 10.5 & 0.50 & $2 \mathrm{Ms}$ & 3 & 8.5 & 0.25 & $5 / 5$ & $8.00 / 7.75$ & $2 \mathrm{Ns}$ & \\
\hline 8 & 90 & 97 & & 5 & 13 & 1.00 & & 3 & 9 & 0.50 & 2 & 8.00 & & \\
\hline 9 & 98 & 107 & & 5 & 14 & 1.00 & & 6 & 100 & $1.00 / 0.50$ & & & & \\
\hline 10 & 108 & 117 & & 3 & 10 & 1.00 & & & & & $4 / 3$ & $8.00 / 7.75$ & $1 \mathrm{~N}$ & \\
\hline 11 & 118 & 129 & & 3 & 12 & 1.00 & & 6 & 100 & 1.00 & $3 / 2$ & $8.00 / 7.75$ & & \\
\hline 12a & 130 & 137 & & 4 & 9 & 0.50 & & & & & 3 & 7.50 & $2 \mathrm{As}$ & \\
\hline $12 \mathrm{~b}$ & 138 & 143 & & 3 & 9 & 0.75 & & & & & 4 & 7.50 & & \\
\hline 13 & 144 & 149 & & 3 & 10 & 1.00 & & 3 & 8 & 0.25 & 2 & 7.50 & & \\
\hline 14 & 150 & 161 & & 3 & 9 & 0.50 & & 4 & 8 & 0.25 & 7 & 7.25 & & \\
\hline 15 & 162 & 179 & & 5 & 8 & 0.25 & $1 \mathrm{~N}$ & & & & 13 & 7.00 & & \\
\hline 16 & 180 & 195 & & 3 & 9 & 0.50 & & 5 & 8 & 0.25 & 10 & 7.00 & & \\
\hline \multirow[t]{3}{*}{17} & 196 & 205 & & 4 & 8 & 0.25 & & & & & $3 / 3$ & $7.50 / 7.00$ & & \\
\hline & & & & \multicolumn{8}{|c|}{$\mathrm{AC}$} & & & \\
\hline & & & & $n$ ir & es corne & ring, $n$ in & ficates $\mathrm{nc}$ & ering & & & & & & \\
\hline
\end{tabular}

Fig. 30 Summary of characteristics of all the Groups

\section{Bibliography}

Arnold, D. 1991. Building in Egypt: Pharaonic Stone Masonry. New York: Oxford Press. Bruchet, J. 1965. Nouvelles Recherches sur la Grande Pyramide. Aix-en-Provence: La Universitain. Clarke, S. and R. Engelback. 1930. Ancient Egyptian Masonry. London: Oxford Univ. Press.

French Govt. 1809-22. Description d'Egypte - recueil des observations et des recherches qui ont ete faites en Egypte pendant l'expedition de l'armee francaise - Tome Premier. Paris.

Gillings, J. 1981. Mathematics in the Time of the Pharaohs. New York: Dover. 
Goyon, G. 1978. Les Rangs d'Assises de la Grande Pyramide. Bulletin de l'Institut Francais d'Archeologie Orientale (BIFAO) 78: 405-413.

Grobert, J.F.L. 1801. Description des Pyramides de Ghize et de la Ville de Kaire. Paris: Logert-Petiet. McKenzie. 1984. A Partial Set of Measurements of the Courses of the Great Pyramid. Unpublished. Petrie, Sir W.M.F. 1883. The Pyramids and Temples of Gizeh. London: Field\& Tuer.

Rossi, C. 2007. Architecture and Mathematics in Ancient Egypt. Cambridge: Cambridge Univ. Press. Smyth, C.P. 1867. Life and Work at the Great Pyramid. Edinburgh: Edmonton \& Doyles.

Walpole, Rev. R. 1817. Memoirs Relating to European and Asiatic Turkey. London: Longman et.al.

Douglas McKenzie obtained a BS in Engineering Physics from Cornell University. The first half of his career was with Exxon.designing and developing computing tools for mechanical, machinery, hydrodynamic and chemical engineers. The second half of his career was as a casualty actuary with various reinsurance companies. He is a Fellow of the Casualty Actuarial Society. His interest in the pyramids began with his first trip to Egypt in 1976. After 3 days of walking around the Great Pyramid he came to the conclusion that there was a reason for the uneven course thicknesses and that with his professional analytical and mathematical skills he might unravel that reason. 